\title{
USE RFID TO ESTABLISH SITE BUILDING MATERIAL MANAGEMENT SYSTEM
}

\author{
Yan-Chyuan Shiau \\ Chung-Hwa University, Hsin-Chu, Taiwan \\ ycshuau@ms22.hinet.net \\ Ming-Teh Wang \\ Chung-Hwa University, Hsin-Chu, Taiwan \\ mtwang@chu.edu.tw \\ Meng-Jia Yeh \\ Chung-Hwa University, Hsin-Chu, Taiwan \\ D0980322@chu.edu.tw \\ Shang-Fong Chen \\ Chung-Hwa University, Hsin-Chu, Taiwan \\ E09616006@cc.chu.edu.tw
}

\begin{abstract}
The demands of building materials are often schedule-orientated during execution of a construction project. In this study, RFID, ER Model, database and IT environment were used to develop the "Site Material Management System". This system integrates site material control which assisted construction companies to execute material management on construction site. The system gathered related information such as activities, materials, required schedule, quantity and material providers. When the inventory amount reach alert level, the system will automatically generate related message and informs the upstream company to purchase material according to the preliminary schedule. The system can help construction companies accurately control the purchase time, prevent work suspension due to material waiting, and reduce storage cost to assure the success of a project.
\end{abstract}

\section{KEYWORDS: RFID, material management}

\section{OBJECTIVE OF STUDY}

In this study, RFID, ER Model, database and IT (Information Technology) environment were used to develop the "Site building material management system" for integrating information of construction site, which mainly discussed the IT application on development of site building material management system. The physical objectives of study include the following:

1. Discuss literature review on relevant field studies in domestic and international terms, as well as current status of site admission, material receiving and resource distribution of building material. Furthermore, the demand of establishing system function and module was confirmed via expert interview. 
2. Use ER Studio to build the system frame that includes database, columns, properties, PK, FK and relations in between, as well as developing the software "Site building material management system”.

3. Verify and test the system functions through cases for proving the correctness of RFID integration and data calculation between each module.

\section{DISCUSSION ON INTRODUCING RFID TO THE SYSTEM}

\section{Building material management}

The high price, long duration and high uncertainty (e.g. work schedule and price of building materials) of construction works make cost control extremely difficult (Peng N. H., 1999). Since building materials occupy an extensive proportion in cost (Chang C. C., 1996) (Chen T. L., 1987) (Yang C. C., 2008), premature site admission of materials would cause increase of storage cost; yet late site admission of building materials would cause delay in works. Therefore, if software could be used to control what materials should be used on which work items, entered at what time and provided timely, smooth work execution may be ensured.

\section{Load information of building materials with scheduling software}

This study used MS Project as the tool to convert data into MS SQL format via ODBC. The project personnel could then use the data managed by original work progress and need not to enter relevant data into the system separately, which saved time and prevented human error.

\section{Coding of building materials}

The study used the outlined coding set by the Public Construction Commission as coding basis of work items in the project. The price of materials in the database was based on the public price in Volume 23 of September 2009 in Northern District of Taiwan (Public Construction Commission, Executive Yuan, 2009).

\section{Selection of RFID hardware}

Considering the cost, reading distance and label characteristics of each frequency, a passive UHF (Ultra High Frequency) was used as the study tool. RFID hardware data used in this study are as follows:

(1) Reader: Imping UHF-Speedway Reader

(2) Dimension: $30 * 21 * 3 \mathrm{~cm}$

(3) Reading distance: $3 \mathrm{~m}$ (depending on the label)

(4) Communication format: EPC C 0/0+/1/1Gen2, ISO-18000-6C

(5) Communication port: TCP/IP

(6) Label type: UHF label

(7) Label dimension: $8.5 * 5.5 * 0.2 \mathrm{~cm}$ 


\section{Operation procedures}

The roles in material management system used on construction site include the owner, architect and construction company. With the RFID equipment was erected at the site entrance, the following procedures of admission and receiving of site materials are as following:

A. The work personnel ordered material according to time of material type, quantity, time, manufacturing deduction, transportation and inspection required for each item under the work schedule.

B. The material supplier prepared the building material according to type and quantity on the purchase order and attached labels at suitable positions as requested.

C. When the materials arrived, the site personnel would check the delivery sheet for material type, quantity and dimension by using a reader to read the RFID label. After that, the site building material management system automatically created an admission sheet and updated the inventory.

D. Work personnel received the building material according to the work progress. The remaining materials were returned to the storage room before off-hours or placed on-site for use on the following day. Administration personnel then established the return sheet, which updated the material to inventory of the site building material management system.

\section{SYSTEM ANALYSIS}

\section{System frame}

The main modules of the "Building material management system" established in this study mainly include Basic data, Common data, Project management, and Material management and as shown in Figure 1.

\section{Establishment of database}

The logical relationship between content of entity and each unit for the database was designed with ER/Studio. The entities and logical relationships formed the logical model, and then generated a physical model via ER/Studio. Such physical model was then connected through ODBC Data Source to SQL Server to import all physical models and establishment physical database (as shown in Figure 2). The logical chart and physical chart of ER Model are shown in Figure 3 and Figure 4.

\section{SYSTEM OPERATION AND CASE VERIFICATION}

The main menu is divided into four groups as shown as the left side frame in Figure 1. The sub-items of each menu are listed under the main menu. Each function description for each sub-item is listed next to sub-item. 


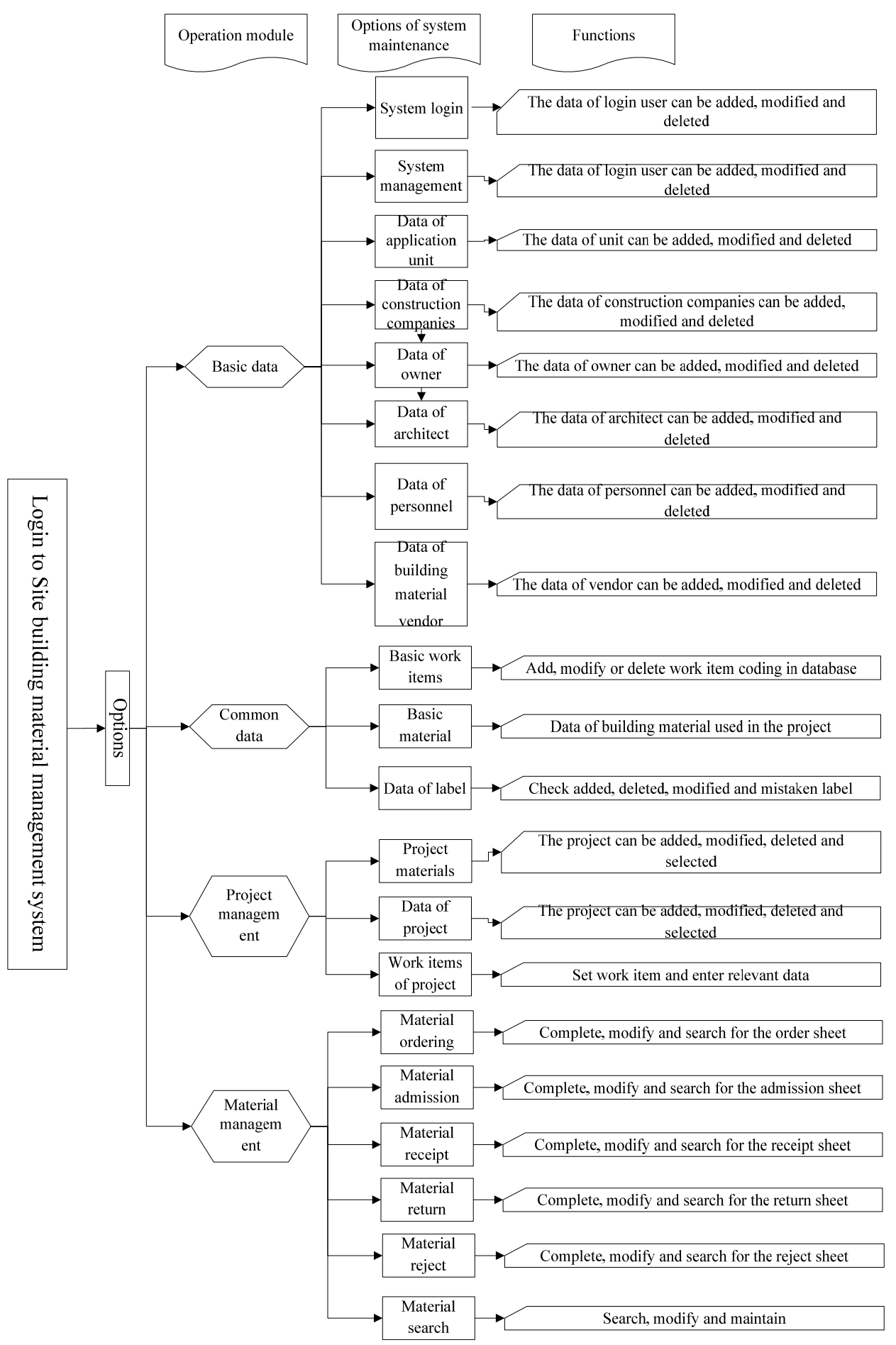

Figure 1: System frame

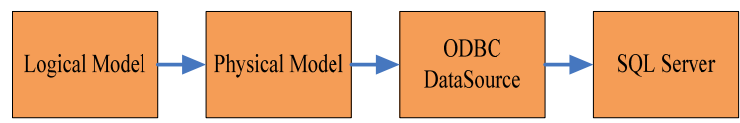

Figure 2: Data conversion procedures 


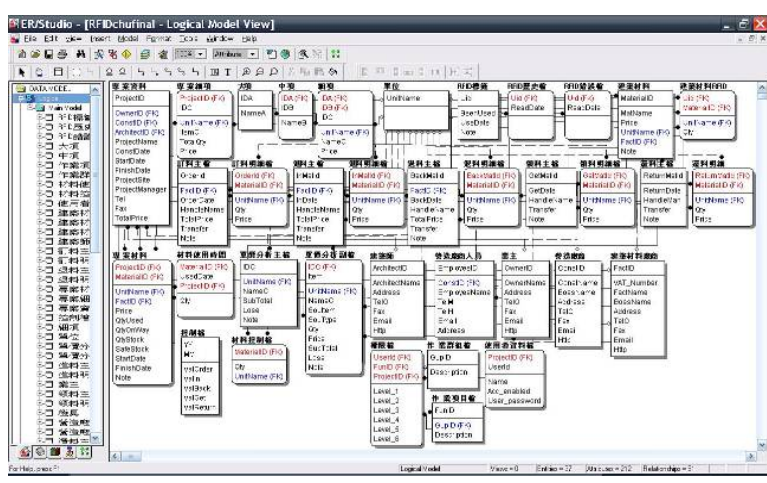

Figure 3: Logic chart of E-R Model

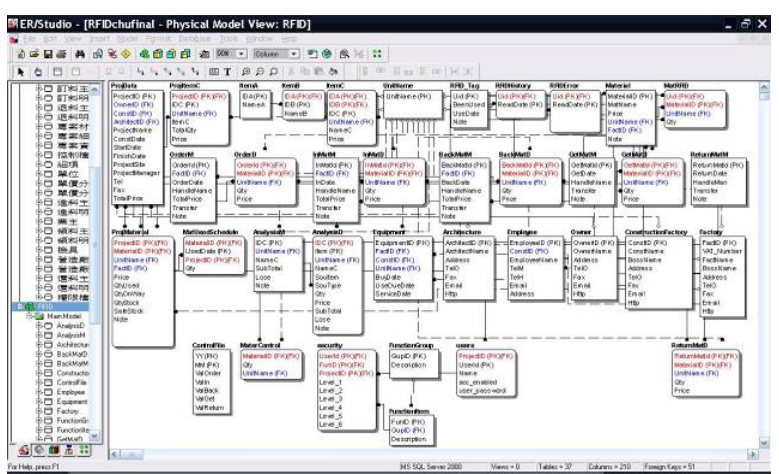

Figure 4: Physical chart of E-R Model

\section{System operation}

\section{Basic data}

The operation for basic data mainly add, delete and modify basic personnel and system data in the database, which includes "System management", "Application unit", "Data of construction company", "Data of owner", "Data of architect”, "Data of personnel” and "Data of material vendor".

\section{Common data}

The operation of common data includes "Basic work items", "Basic materials" and "Data of label". The "Basic work items" is shown as Figure 5; when the major item is clicked, the system automatically displays the sub-item below and when the sub-item is clicked, the system automatically displays the detailed items. In the case of searching for the content of outlined coding, the button "Display content" can be clicked and the system will list all items.

When certain material is clicked in the screen of "Basic materials", the system will display relevant details on the right side of screen, so the user can edit or add new building materials (as shown in Figure 6).

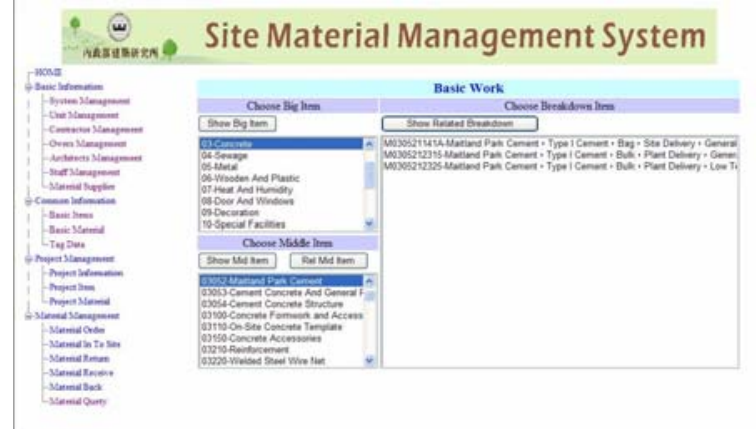

Figure 5: Window of basic work items

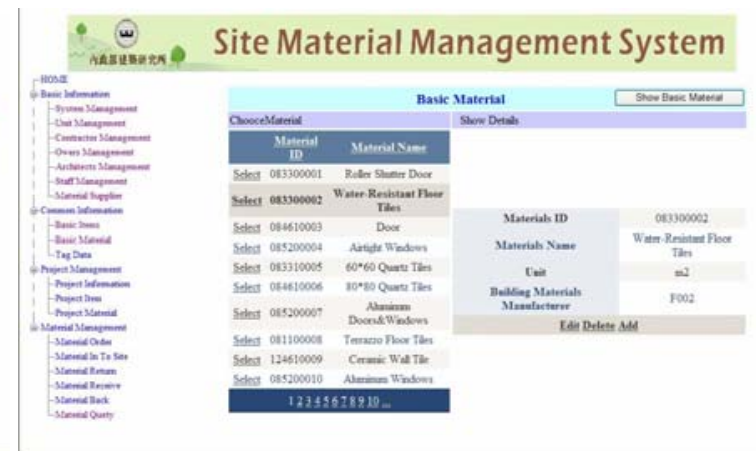

Figure 6: Window of basic materials

\section{Case input}

\section{Input project data}


In the maintenance screen of project data developed from this study (as shown in Figure 7), the project data can be edited and added. The user can also click the button "Display project data" on right side of the management screen and the system will automatically display the project data.

\section{Input project work items}

The "Maintenance window of project work items" in the system (as shown in Figure 8) allows the user to set work items for the project. The user can select major items, less important items and detailed items on the left side, and then click the button "Input project work item" to add such work item into the project. After entering the total quantity and adjusting the rate, the setting of project work items may be completed easily.

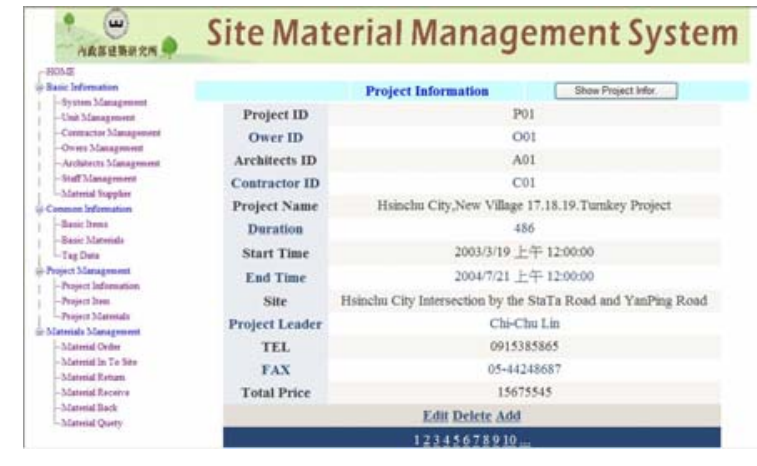

Figure 7: Window of project data

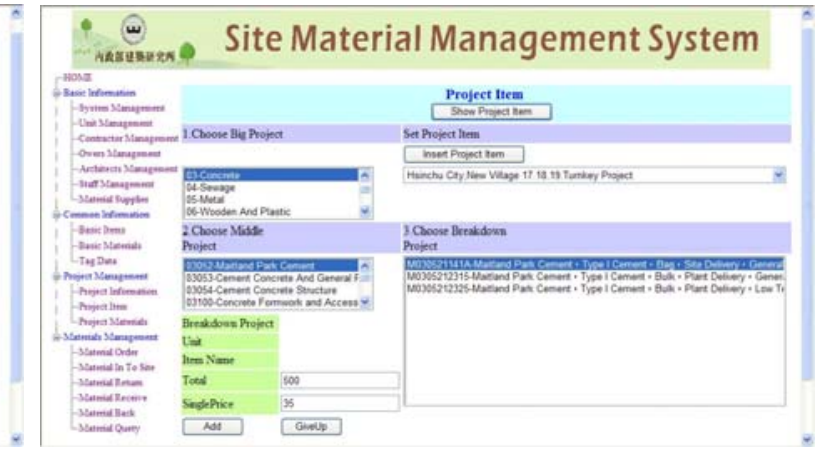

Figure 8: Window of project work items

\section{Input project material}

In the "Maintenance window of project material" (as shown in Figure 9), the user only needs to select the project number, material number, material unit, material vendor and then input the quantity to be used and safe inventory. After confirmation, press "Save" to store the material into the project.

The construction period for general projects would often be adjusted due to certain factors during execution, which further impact the usage time for building materials. The user only need to click the button "Update usage time of project material" and the system will read the latest date updated in the project and update the usage duration of relevant building materials.

If the user needs to understand detail data of the project materials, the button "Display project material" and the system will show the checklist of materials used in the entire project for reference.

\section{Maintenance of material ordering}

The maintenance window for "Material ordering" of the system (as shown in Figure 10) can be utilized by the user for task of material ordering. The system can base on the date and automatically number the order. After selecting material number and quantity, the system can automatically calculate total price of the order when the button "Calculate total" is pressed. When the button "Display details" is pressed, the system can show each detailed data for specific order. All other operations of material sheet in the system are the same. 


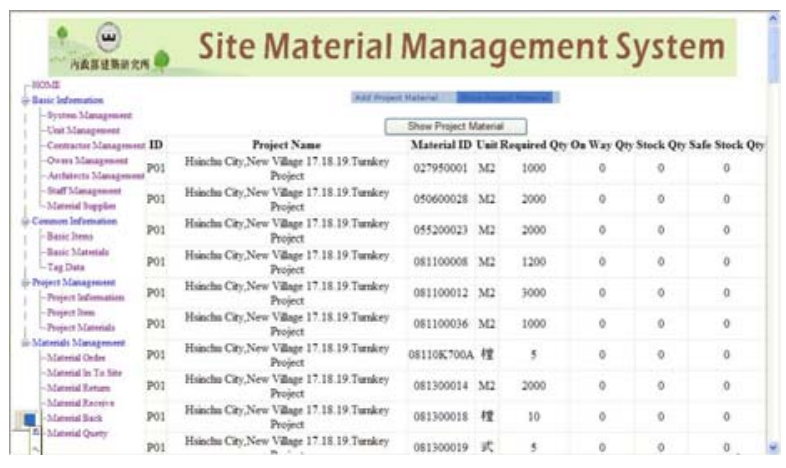

Figure 9: Project materials maintenance

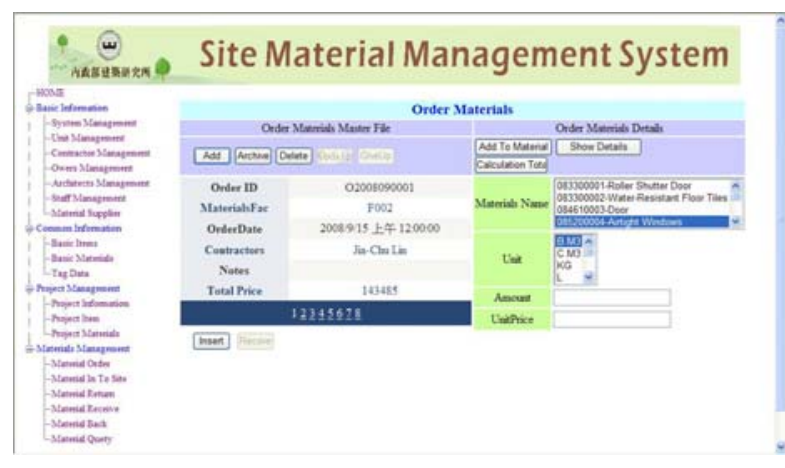

Figure 10: Ordering materials maintenance

\section{Maintenance of material search}

In the "Maintenance window of material search" (as shown in Figure 11), the user can search the "Order sheet", "Admission sheet”, "Reject sheet", "Receipt sheet" and "Return sheet" separately, which include search conditions such as "Number", "Date" (including the date after certain date, between two certain dates and after certain date), "Vendor" and "Material". More search conditions would generate smaller and finer scope of search results, where the user could base on the need and perform conditional search in stages. The search results are as shown in Figure 12.

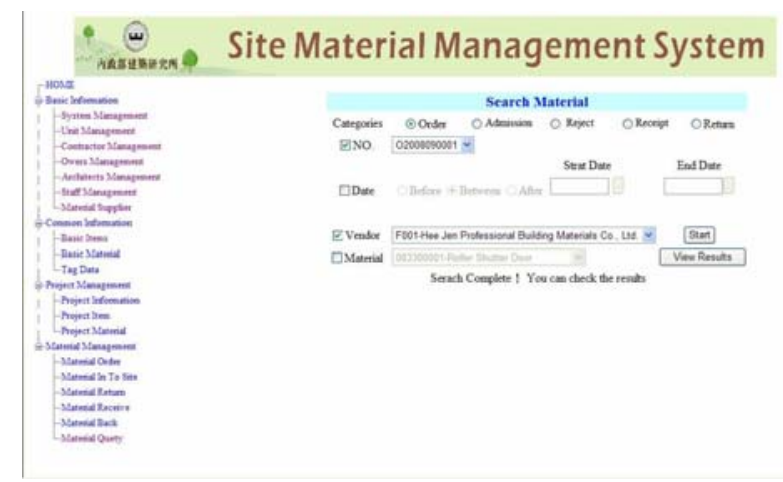

Figure 11: Maintenance window of material search

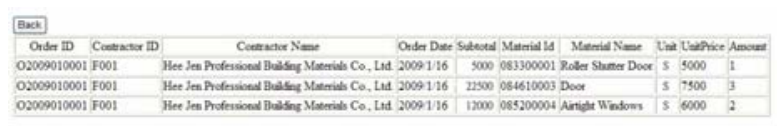

Figure 12: Result screen of material search

\section{System characteristics}

The characteristics provided by the site building material management system established under this study are as follows:

\section{Unified style}

The system uses Master Pages and the same design style for unified operation screens and great convenience.

2. Rich data input in advance

The system was built-in with rich data. The work items and building materials were coded according to the outline of Public Construction Commission, which connects with the 
industry and public department. The built-in price of materials for northern Taiwan was the public price of material in September 2009 for high level of reference.

\section{Convenience of data selection}

All vendors, units and building materials built into the system is provided with function of pull-down search and can be automatically connected from the system. Furthermore, medium items can be automatically listed from major items and detailed items from medium items according to the numbering of Public Construction Commission, which provide great availability when setting work items used in the project.

4. Automatic numbering of material sheet

All five types of material sheets can be automatically numbered separately according to months, which save the irritating trouble of numbering.

5. Regulated database

The internal data was processed with regulated design and the resources consumed was less. In addition, when the column of each database gets used by other data, such column will be locked automatically and not deleted for prevention of mistake.

6. Linked integration for all material sheets:

(1) When the order sheet imports to (restores) the system, the scheduled receipts of system material increases (reduces).

(2) When the admission sheet imports to (restores) the system, the scheduled receipts of system material reduces (increases) and the inventory increases (reduces).

(3) When the return sheet imports to (restores) the system, the scheduled receipts of system material increases (reduces) and the inventory reduces (increases).

(4) When the receipt sheet imports to (restores) the system, the inventory of system material reduces (increases).

(5) When the return sheet imports to (restores) the system, the inventory of system material increases (reduces).

7. Integration of RFID and the system

Upon admission of building material where the RFID Reader detects the label and writes into the database, the admission sheet can be produced automatically by pressing only one button when the unused label is confirmed, which provides the effect of integration.

8. Dumb-proof measure

The RFID label is provided with dumb-proof function and automatically locked once being used, thus there will be no mistake of repetitive use that generates false admission.

9. Interface integration 
On the same screen, each material sheet is allowed for relevant crossed searching and printing with consideration factors include material sheet number, date (including the date after certain date, between two certain dates and after certain date), vendors and materials.

10. Development of network interface

This study uses the network interface of ASP.net for development, which can be operated via Browser, so the system can bring out powerful effect and rapidly manage information of building material on site.

\section{Consideration of multi-user interface}

The design of internal data transmission adopts the database and internal element instead of files and public variables, which ensures a web environment of multi-users and not causing mistaken entry of unexpected information.

12. Integration of scheduling software

The system can synchronize the usage time of building materials with the scheduling software by importing the data of Project schedule, which saves hassle of repetitive data entry and prevent human negligence.

\section{Benefit evaluation}

This study used the MS SQL Server database management system that applies the ER Studio as the tool to establish the database frame. The MS Visual Studio was used to develop site building material management system, which performs function test of individual system by entering the case data. The target of benefits generated from the system mainly includes the owner, construction company and supervision unit as shown in Table 1.

Table 1: Benefits from the site building material management system

\begin{tabular}{|l|l|}
\hline Target & Benefits \\
\hline \multirow{5}{*}{ Owner } & 1. Transparent and open information \\
\cline { 2 - 2 } $\begin{array}{l}\text { Construction } \\
\text { company }\end{array}$ & $\begin{array}{l}\text { 2. Procedures and status of material ordering and admission from vendors can be } \\
\text { understood from the system }\end{array}$ \\
\cline { 2 - 2 } Supervision unit & 2. Real-time information management \\
\cline { 2 - 2 } & 3. Deficiency of management manpower can be smoothed effectively \\
\cline { 2 - 2 } & $\begin{array}{l}\text { 1. Reduction of paper work } \\
\text { understood from the system }\end{array}$ \\
\hline \multirow{5}{*}{ Others } & 1. Improvement of industrial competitiveness \\
\cline { 2 - 2 } & 2. Reduction of data transmission time \\
\cline { 2 - 2 } & 3. Reduction of human error \\
\cline { 2 - 2 } & 4. Paperless operation \\
\cline { 2 - 2 } & 5. The label recycling achieves requirement of environmental protection \\
\hline
\end{tabular}




\section{CONCLUSIONS AND SUGGESTIONS}

\section{Conclusions}

1. The system developed a search interface that allows user to search content of building materials on site, which improve Construction Company's control on building material database, construction speed and corporate competitiveness, as well as providing the companies a path to follow. The cooperation with RFID characteristics enhanced correctness of building material management, reduced inventory cost and idle materials, as well as preventing work suspension and reducing pressure of fund procurement.

2. After entering the case of turnkey construction of Village no. 17, 18 and 19 in Hsinchu City, all relevant functions of the system could operate correctly, thus the system could be used on site for relevant material management and improves the management ability of construction industry.

\section{Suggestions}

1. Based on cost consideration, the user can set multi-angle antenna for method of building material management, which enhances the rate of correct reading.

2. When the development of RFID equipment in domestic industry reaches certain level, the purchase of domestic products can effectively reduce the cost.

\section{REFERENCES}

Peng N. H. (1999) "Application of inventory theory on material procurement program for construction project”, Topical research program under National Science Council, Executive Yuan.

Chang C. C. (1996) "A study of incorporating JIT concept with PERT on construction procurement”, Master thesis, Institute of Business Management, National Chung Hsing University.

Chen T. L. (1987) “Construction management - Work schedule of construction project”, Taiwan Construction Research Institute.

Yang C. C (2008) "Mode of inventory theory under uncertain requirement”, Topical research program under National Science Council, Executive Yuan.

Public Construction Commission, Executive Yuan (2009) Public construction technical database, available at: http://pcces.archnowledge.comcsi/ 